\title{
NARRACIONES IDENTITARIAS, VIOLENCIA, POLITICA Y CIVILIDAD: EL PSICOANALISIS FRENTE A LOS ENSUEÑOS COLECTIVOS
}

\author{
Alejandro Bilbao ${ }^{1}$ \\ Daniel Jofré ${ }^{2}$
}

\begin{abstract}
Resumen: El presente artículo establece un análisis relativo a los sentidos que organizan las narraciones de las políticas identitarias, considerando sus vínculos históricos y sociales con la dimensión de la violencia extrema. Para ello, se toman en cuenta ciertos alcances históricos de la filosofía política, analizando las relaciones que estos evidencian con las propuestas freudianas relativas a la dimensión cultural de la política. Un número igualmente importante de enunciados es elaborado a propósito de las acciones políticas que pueden ser establecidas frente al curso
\end{abstract}

Palabras claves: Violencia. Política. Identidad. Civilización. Psicoanálisis.

D’avoir désigné que la politique est irreprésentable, parce qu'elle fait sujet dans l'ordre perceptible du symptôme, fait de Marx un penseur de la politique dégagé du politique, dont il fixe la fiction. Ce n'est pas d'une norme qu'il assure, mais d'un "il y a" d'évènement, où il croise un réel, dans l'impasse de tout ordre concevable et représenté. La vérité de la politique est dans le point de ce "il y a", et non dans son lien.

BADIOU, 1985, p. 20)

1 Investigador Departamento de Humanidades y Artes Universidad de los Lagos. Investigador Asociado FONDAP (151100006). Universidad de Los Lagos, avenida Fuchslocher 1305, Osorno, Chile. Teléfono: 5663 2221329, e-mail: manuel.bilbao@ulagos.cl, (D) https://orcid.org/0000-00028064-0694

${ }^{2}$ Instituto de Psicología, Universidad Austral de Chile. Investigador Asociado FONDAP (151100006). Universidad Austral de Chile, Sede Puerto Montt, casilla 1327. Teléfono: 65 2277153, e-mail: daniel. jofre@uach.cl, (D) https://orcid.org/0000-0002-7902-4704

http://dx.doi.org/10.1590/0101-3173.2020.v43n4.02.p17 


\section{INTRODUCCIÓN}

Toda sociedad posee formas específicas de nominación para determinar lo que considera propio y singular, el dominio indivisible de su "unidad cultural”. El trabajo que se asienta al interior de estas formas de nominación, no solo esboza los valores nacionales e identitarios del grupo social, pues permite trazar lo que una sociedad deja de ser al nombrar los motivos de su excepcionalidad histórica. En la construcción de tal “espíritu colectivo," obran estructuras narrativas que brindan el sostén requerido para la colonización de parajes naturales, la institución de fronteras y la homogenización de los individuos. La organización del espíritu nacional requiere del establecimiento de procesos de identificación entre los miembros del grupo, identificaciones que las estructuras narrativas intentan desarrollar por medio de los instrumentos que brinda la institucionalidad de la política. Estos relatos identitarios, son también una modalidad de canalización de las tendencias destructivas que habitan en las sociedades, mostrando en cuanto los procesos de habitación cultural operan por medio de referencias constantes a las figuras del amor, del odio, de la agresión y de la violencia. Las derivas de demarcación de los sentimientos identitarios han obrado de un modo histórico en la constitución de los nacionalismos, en las empresas coloniales y en el acrecentamiento actual de los fundamentalismos religiosos y de Estado. De algún modo, la declinación de la política en el contexto contemporáneo, ha permitido el robustecimiento de estos discursos, como una forma de reacción a las inconsistencias que esboza su institucionalidad. Las pasiones identitarias poseen por vocación colmar el dominio de las incertidumbres que acechan a las comunidades por medio de la instauración de sentidos extremos, afianzados en lecturas "románticas" del ser nacional, o por medio de la instauración de un tipo de genio étnico. Para la democracia política, los sentidos extremos de estas narraciones afectan un aspecto esencial de su existencia como es su pervivencia en el tiempo y en el trascurrir de las generaciones. La exaltación del odio, de la agresión, el acecho que las diferencias ejercen a la mismidad idiosincrática, y su consecuente amenaza a la identidad nacional, son móviles que, siendo intrínsecos a este tipo de narraciones, pueden conducir a la posibilidad efectiva de socavar los principios de la democracia política. La tarea que se ve de este modo abierta para la política, es cómo resistir frente al acrecentamiento de tales sentidos totalizadores.

Pero, ¿cómo entender los sentidos que transitan por estos tipos de narraciones e imágenes? ¿Cuál es el rol que finalmente estas narraciones 
cumplen en la organización de la vida social? ¿Por qué estos relatos junto con apelar a la unidad del grupo social, develan un importante espacio de expresión para el temor, el racismo, la ira y el odio? ¿Cuáles son sus fundamentos? ¿En qué tipo de incertidumbres estas formulaciones narrativas se apoyan para conmover pasiones que adquieren como correlato la exclusión, el odio y la destrucción de lo considerado diferente?

La intervención de variables de múltiple procedencia en el análisis de estos problemas, convoca la producción de enunciados históricos, sociales, filosóficos y religiosos necesarios a los efectos de su comprensión. Las hipótesis vertidas en el presente texto, intentan localizar los puntos de anclaje que la dimensión política mantiene con cada uno de estos enunciados.

La argumentación propuesta se desarrolla en cuatro títulos. El primer título, El conflicto de las identidades y los fundamentos de su nominación, aborda la lógica interna de las formulaciones contractualistas del derecho, la construcción colectiva de los sentidos políticos y el surgimiento de las "pasiones identitarias" al interior del marco que define la idea de Nación. El segundo título, identidades, políticas y violencia, indaga en la abolición de los sentidos políticos de la democracia -sean estos ideológicos, míticos o religiosos-. Este segundo aspecto del texto, asocia la interrogación por la forma de expresión de la glorificación identitaria a las nociones de subjetividad y de resistencia como una parte integral de los análisis referidos a la violencia de las narraciones identitarias. El tercer título de este trabajo, Hobbes, Hegel, de la crueldad de la violencia a la violencia hecha poder, se detiene en el plano de las elaboraciones históricas construidas a propósito de la contraposición entre la lógica contractual y la condición natural del hombre. Aborda las indagaciones de Hobbes y de Hegel con el objeto de considerar la articulación de las leyes naturales con el dominio del orden consensuado de la razón y del contrato. De ambos autores, se resaltan las ideas de represión y conversión de la violencia, exponiéndolas al interior de sus respectivas concepciones de origen. De suerte que, por medio de una lectura referida a las pasiones y la violencia, se enfatizan los aspectos a considerar para pensar la construcción imaginaria de las identidades colectivas, sus fundamentos y su permanencia en el tiempo. El título cuarto, El psicoanálisis frente a la violencia, la política y los relatos identitarios, se dirige a considerar estos problemas a partir de las puntualizaciones que el psicoanálisis organiza respecto de los motivos políticos-culturales, su vinculación con la violencia y los sentimientos identitarios. Finalmente, se destaca la negatividad 
actuante en las tesis de Freud para pensar la violencia inserta en la historia, insertandola en una dimensión ética y política de la subjetividad.

\section{El CONFLICTO DE LAS IDENTIDADES Y LOS FUNDAMENTOS DE SU NOMINACIÓN}

Toda sociedad posee una forma de nombrar su singularidad por los medios que ella misma convoca para diferenciar lo considerado propio de lo distinto, lo idéntico de lo extraño. Estas formas de nominación y distinción, operan por medio de tramas narrativas que brindan al grupo social el estado de la excepción requerida, otorgándole la apropiación de su "espíritu singular". Las estructuras narrativas son útiles al grupo social para inscribir su paso en el tiempo y en la historia, permitiéndole establecer sus condiciones de existencia por medio de la presencia de un tipo de "genio étnico" (APPADURAI, 2007, p. 16) que las tramas narrativas se encargan de preservar y transmitir entre las generaciones. El afán identitario surge así promovido por la prestancia de imágenes y relatos, que brindan el marco de las representaciones que son requeridas a los efectos de construcción de la identidad imaginada. Pero, ¿cómo entender los sentidos que transitan por estos tipos de narraciones e imágenes? ¿Cuál es el rol que finalmente estas narraciones cumplen en la organización de la vida social? ¿Por qué estas narraciones junto con apelar a la unidad del grupo social, develan un importante espacio de expresión para el temor, el racismo, la ira y el odio? ¿Cuáles son sus fundamentos? ¿Qué tipo de incertidumbre es la que opera en estas formulaciones narrativas, que posee la fuerza de conmover pasiones que pueden adquirir como destino, la exclusión y en ocasiones la destrucción de lo considerado diferente? Un primer análisis relativo a la relación que adquieren las pasiones con las "ilusiones" de la identidad, las devela como un aspecto importante de la existencia de las colectividades. Durante el siglo XVIII, Rousseau observaba en la existencia de las pasiones el modo opuesto de expresión de la institucionalidad de las formaciones políticas (la ley prima sobre el derecho natural), éstas constituyen el reverso negativo de las concesiones que son necesarias para la preservación de la vida colectiva (ROUSSEAU, 1996, p. 113). Reflejo de estas condiciones de existencia son los ciudadanos, unidades insertas en el horizonte infranqueable de la democracia política. Por el contrario, la cimentación de las concesiones necesarias a los sentimientos de unidad y de cohesión colectiva, erigen en apariencia un momento divergente, que descansa en el supuesto de que, en la constitución de las identificaciones sociales, obran motivos políticos laboriosamente forjados, que se asientan en el consentimiento que el hombre 
presta a la enajenación de los derechos individuales (ROUSSEAU, 1996, p. 133). En el estado de naturaleza, la potentia del hombre le permite ejercer su poder de dominación sobre objetos y personas, hasta que un poder de mayor envergadura lo distancie de tal propósito. De este modo, el pasaje al estado político consiste en la renuncia a la potentia, por medio del ejercicio del libre arbitrio, de la razón y de la voluntad. Todas las cláusulas del contrato social remiten finalmente a la alienación total de los derechos naturales, es el modo consensuado de ingreso a la vida social. La figura del hombre-ciudadano se encuentra sometida a la ley, a la voluntad y la potesta, ya sea al servicio de la democracia (Rousseau) o de la monarquía (Hobbes). El derecho natural moderno expresa la existencia del derecho como poder (potentia) de un sujeto originariamente libre, privado de sus derechos bajo la instauración la potestas. El pasaje que va de la potentia a la potestas, se torna la expresión de la soberanía que el consenso ejerce sobre las tendencias individuales. Estas premisas generales del contractualismo político, permiten la organización de los mitos y relatos del contrato social y la emergencia de un poder central (ya sea del Estado republicano o del poder monárquico).

De este modo, se observa que la expresión "pasión identitaria" reúne los dos polos que delimitan la existencia de los pueblos. Por una parte, las pasiones, el ímpetu de la existencia natural, la violencia de tendencias que obran en un sentido contrario a las formas del consenso colectivo. Por otra parte, el mismo vocablo condensa los actos de creación y figuración que son necesarios al forjamiento de los sentimientos de una colectividad, otro modo de nombrar la apropiación de su singularidad histórica, los fundamentos necesarios al establecimiento de su ideario cultural. Para las políticas de afanes identitarios, esta reunión de términos no grafica empero una oposición de sentido, no los distingue por medio de antagonismos y contrastes, sino que los muestra en íntima vinculación con las lógicas que ordenan los tiempos de la política. El énfasis dado en la actualidad a la preocupación por estipular los sentidos que serían propios a una colectividad específica (sus rasgos definitorios, su "mismidad" étnica, el modo singular que poseería para pernoctar en la historia), es inseparable de los móviles sociales y económicos que han sido abiertos por la globalización. La incidencia de este orden global, ha sido importante en el escenario de los nuevos flujos migratorios, así como en el recrudecimiento de las antiguas políticas coloniales observables en el planeta. Sus alcances también se hacen sentir en el dominio de las identidades colectivas, generando reacciones de re-apropiación identitaria que en el plano político, se convierten en la manifestación de identidades amenazadas. Sin 
ser una consecuencia directa del nuevo orden implantado por el capitalismo tardío, el problema de las identidades en conflicto tiende a ser observado como uno de sus alcances mayores, desestimando el rol protagónico que este conflicto posee en la definición de los sentidos que son propios a la organización de una comunidad. Los estados nacionales actuales, conforman precisas narraciones de los antagonismos y contrastes que movilizan estos conflictos, conduciendo a algunos autores a sostener la idea de un choque de civilizaciones (HUNTINGTON, 1997). Rechazando estos supuestos, otros autores han preferido hablar de la instauración de una cultura del miedo, como reacción a la hipotética "esencia" étnica atribuida a los grupos humanos (CREPÓN, 2010, p. 9).

La globalización ha sido un fenómeno que ha exacerbado la presencia de la incertidumbre en las sociedades humanas, produciendo importantes incentivos para la purificación cultural a medida que más naciones pierden el dominio de su soberanía económica y nacional. Esta situación es relevante a fin de observar que la violencia a gran escala no es el producto de identidades antagónicas y/o en conflicto. Si la incertidumbre es el germen de la angustia que las sociedades expresan en lo relativo ámbitos tan diversos como la educación, la salud, y los derechos de vivienda, la violencia actúa como una forma de reacción frente a estas incertidumbres, que la circulación global de objetos y personas produce invariablemente. La violencia no es un elemento que actúa desde afuera de la sociedad para de ese modo afectarla. Esta es la respuesta interna a la existencia de la incertidumbre. La interrogación por la identidad colectiva y nacional es siempre deudora de esta incertidumbre de inicio. No es finalmente una discusión por la identidad lo central en estos tópicos, es la precipitación a un porvenir colmado de incertidumbres.

Para Appadurai (2007, p. 20), la existencia de los fundamentalismos no es una situación que prescinda de esta óptica de análisis.

En ese sentido, el fundamentalismo islámico, el fundamentalismo cristiano y muchas otras formas locales o regionales de fundamentalismo cultural pueden considerarse parte de un repertorio emergente de intentos de producir niveles antes innecesarios de certeza acerca de la identidad social, los valores, la tradición y la dignidad. La violencia, sobre todo la violencia extrema y espectacular, es una manera de producir ese tipo de certeza.

Frente a la incertidumbre, la certeza en la existencia de fundamentos para definir lo que es propio a una comunidad, transita por parámetros de 
diversa naturaleza. Dicho anhelo identitario se forja a través de la utilización de instrumentos históricos, políticos, sociales y religiosos. En el ámbito histórico, estas herramientas conforman parámetros de referencia extraídos de los enunciados del historicismo positivista, patrón conceptual que forja el imaginario que es atribuido al sentido de las tradiciones. Se trata de la tradición que brinda la lengua, la educación, las imágenes y ensoñaciones que colonizan territorios y parajes. Las incertidumbres identitarias son colmadas por medio de las "certezas pedagógicas" que obran en la recreación del espíritu colectivo. La identidad colectiva puede entonces transmitirse, ser vista en las imágenes que son recreadas por los medios institucionales, escuchada en los relatos que son atribuidos a la categoría de Nación, de pueblo y ciudadanía. La transmisión que se actualiza de generación en generación, brinda a los individuos la experiencia de una singularidad de excepción, la grandeza de una identidad común.

El ahínco identitario no desagrega los vínculos que la historia mantiene con la política, los supone por medio de la sedimentación del presente en las figuras de la tradición y del pasado remoto e inmemorial. El pasado se imaginariza como un fundamento inmutable. Por medio de las incertidumbres, las pasiones identitarias nombran el sesgo del apremio, del temor, de la violencia y del miedo que puede atravesar a la vida social. Cabría la necesidad de añadir la angustia de lo incompleto, sensación siempre latente en los proyectos de pureza nacional "completa," y la incertidumbre social relativa a las categorías etnoraciales que definen a gran escala el "ser" identitario. Formas que pueden conducir de un modo desenfrenado a las jerarquizaciones de pureza que estimulan la manifestación de genocidios. Gourevitch indicaba que "el genocidio, después de todo, es un ejercicio que construye sentimiento de comunidad” (GOUREVITCH, 1998, p. 95).

No es sorprendente que la violencia sea un modo de nombrar la política, pensar la violencia es vincularla de un modo innegable a la historicidad del hombre. Sus alcances se encuentran presentes en las creaciones que ésta historia evidencia en el ámbito de las artes, de la literatura, de la moral, de la religión y de la política. De un modo general, este contexto temporal evidencia en cuanto las organizaciones narrativas que las sociedades elaboran para nombrar las "identidades imaginadas" transitan por los dominios y territorios de la violencia. Los idearios de estas formas de nominación identitaria, obran en razón de establecer los modos de representación y figuración de la mismidad anhelada, lo cual supone considerar de un modo constante, las medidas de 
fuerza que la ideología de base busca perennizar por medio de la utilización de violencias explicitas o larvadas. Los relatos identitarios operan por medio de prácticas de "normalización" relativamente inmutables, utilizando instrumentos que tienden a suscitar la colonización interna de los individuos. Como fuera indicado, en el ámbito colectivo, modalidades de estos instrumentos son la educación, la transmisión de la lengua, la modulación cultural de ciertos ritos, la imaginarización que opera en la delimitación de territorios y fronteras. Todos ellos procuran el anclaje identificatorio necesario a los efectos de la homogenización grupal. A través de estas imágenes y relatos, la colonización interna de los individuos evidencia que las fronteras identitarias son siempre fronteras que yacen en el espíritu de las colectividades, en la delimitación que éstas establecen para deslindar lo considerado propio, y determinar de ese modo, lo admitido como extrańo o divergente.

Las representaciones que son necesarias a los objetivos de la nominación identitaria -que estipulan la permanencia de imágenes y relatos-, reúnen una trama importante de elementos diferenciadores que cumplen con permitir la organización de dichas nominaciones. La homogenización de las imágenes que obra en las bases del historicismo positivista, es una fracción importante de los anhelos identitarios de las políticas nacionalistas, modo ejemplar de la reificación de los sentidos que operan al interior de los actos narrativos y nominativos de las sociedades. El encomio ideológico presentado sistemáticamente por los estados nacionales en lo referido a la uniformización de los individuos, es un buen ejemplo de los elementos que refuerzan la creación de las "identidades imaginadas". Al amparo de una idea de Nación y de pueblo (de su historia, de sus imágenes, y relatos), la uniformización se define como una categoría relevante de la distribución identitaria, estableciendo el cuerpo de las jerarquizaciones que permiten organizar la posición que los individuos poseen al interior del relato nacional del grupo social. El sentimiento de pertenencia de los individuos, también es una consecuencia del narcisismo colectivo que estas narraciones actualizan por medio de sus configuraciones relativas al "ser nacional". Estas narraciones no solo exhiben fenómenos de uniformización colectiva que actúan de un modo interno a la colectividad, también develan los grados de tolerancia que son admitidos en las distancias que los individuos expresan frente al tipo de "genio étnico" que intenta ser propiciado. La tolerancia emerge de este modo como una forma de admisión de las diferencias, pero establecida desde las concesiones que impone una sociedad que se representa por los medios de la dominación. Esta no admite el contexto ni los márgenes del reconocimiento que debe ser dado a las diferencias, 
simplemente opta por tolerar lo considerado diferente al discurso étniconacional. No conceder en el reconocimiento, pero si en la tolerancia, es una de las formas de totalización de los sentidos políticos del espacio público, fuente de discriminación y estimulación en el surgimiento de violencia. El relato racial de la política nazi obró por medio de estas distinciones, inicialmente tolerando (aunque en la marginalidad) la presencia de seres indeseables en el espacio público, para posteriormente despropiarlos del reconocimiento del derecho de ciudad y de la individualidad que es expresión de ese derecho. Las políticas migratorias de una parte importante de los estados europeos de fines de los ańos sesenta y setenta del siglo XX, vieron emerger más tardíamente las consecuencias de las distancias sociales propiciadas por ambos tipos de fenómenos, sobre todo en las terceras generaciones de estos inmigrantes, que son hoy presa de discursos identitarios radicales, conductores de la violencia y el odio que es dirigida contra esos mismos estados (por medio del llamado a la yihad o a través de la violencia que se expresa en sus suburbios). Las distancias y cercanías que se expresan al interior de la vida social entre la tolerancia y el reconocimiento que es dado a los individuos, son también manifestaciones de los alcances de las narraciones identitarias, de las cercanías que los individuos mantienen con el tipo de identidad imaginada.

La forma histórica asumida por los relatos imperialistas y colonialistas, en los modos de organizar un sistema representativo para considerar la existencia de otras identidades, es sin duda una ejemplificación de la trama de elementos de distribución y jerarquización que operan en la nominación de lo considerado diferente, incorporando indudablemente la faceta segregativa que brinda el carácter de irreproducible a la sociedad dominadora. Las prácticas políticas de los estados modernos poseen también una deriva colonizadora de carácter interno -imposible de soslayar-, que se expresa a través de los modos siempre violentos que posee para introducir una idea de Nación, de ciudadanía y de individuo. Estas prácticas son ejercidas y perpetuadas en poblaciones de orígenes diversos, pero asentadas en un mismo territorio (grupos étnicos minoritarios, poblaciones indígenas). Debe finalmente admitirse que la violencia ha sido un medio de legitimación de las formas de nominación y narración de las identidades, ocupando un lugar significativo en los modos que las sociedades poseen para elaborar sus representaciones de habitación en el devenir histórico. 


\section{IDENTIDADES, POLÍTICA Y VIOLENCIA}

En el dominio de desenvolvimiento del espacio público, la existencia de la violencia identitaria sugiere en ocasiones la abolición de los sentidos que obran al interior de la institucionalidad política, configurando un territorio de excepción en su funcionamiento. La violencia se convierte en este caso, en el modo de expresión del peligro y de la amenaza, suspendiendo la acción de los sentidos posibles. Empero, tal suspensión solo se dirige a los sentidos que trasmite la institución política, el déficit o la pérdida de sentido no conduce forzosamente a los umbrales del nihilismo político. Estos sentidos no "sancionados", pueden suscitar nuevos procesos de fabricación de cosmovisiones de mundo, cuyo carácter artificial desemboca frecuentemente en prácticas y discursos radicales que "deslegitiman sus propias creaciones" (WIEVIORKA, 2009, P. 94). En ciertas experiencias, la violencia puede de este modo apoyarse en ideologías que legitiman los sentidos de sustitución, como es el caso de ciertas formas de terrorismo. En otras circunstancias, es un mito el que pone en juego una construcción discursiva que integra los elementos de los sentidos desfallecientes. En estos casos, la violencia se desenvuelve hasta los límites o umbrales en que el mito se sostiene; la presencia de los actores políticos cumple y refuerza las posibilidades de proyección de los sentidos del mito, extendiendo las posibilidades efectivas de su perduración en el tiempo. El mundo contemporáneo da pruebas incontrastables del lugar que la religión cumple en la organización de tales mitos, aportando sentidos metapolíticos a las acciones violentas que trascienden la dimensión política. La religión se emplaza de este modo como "un fundamento posible de la política" (RANCIERE, 2005; ENRIQUEZ, 2007).

De igual modo, existen otros aspectos de la violencia propiciados por la deriva identitaria, formas emanadas del tipo de acción política que ésta enarbola en la búsqueda de sus fundamentos raciales, étnicos o sociopolíticos. Si es una política de sentidos extremos la que organiza la búsqueda de tales fundamentos, es también extrema la forma de considerar las diferencias emergentes. Es el caso de la violencia asociada a la crueldad, ejemplarmente visible en la veta genocida y exterminadora por medio de la cual las diferencias intentan ser abolidas. En estos casos, la glorificación identitaria arraiga un tipo de subjetividad ausente, motivo de las "irresponsabilidades" por obediencia a una autoridad legítima y superior tal y como ha sido precisado por Hannah Arendt a propósito del genocidio nazi (1972). El encomio identitario también puede desplazarse en la dirección de la destrucción de la propia 
individualidad, visible en las acciones terroristas del "agente destructor" que, en sus acciones destructoras dirigidas al otro, no omite la aniquilación de la propia individualidad.

Estos mínimos aspectos de una fenomenología de la violencia, que trascurren en el territorio de las subjetividades ausentes y de destrucción de la individualidad, indican que el recurso a la categoría de la subjetividad puede revelar una importante variable de análisis para una crítica de la violencia identitaria. Determinar frente a este tipo de violencia el punto dónde deben establecerse los umbrales de rechazo, supone la inclusión de los sujetos que políticamente pueden organizar acciones de respuesta y resistencia frente a este tipo de violencia.

Un primer aspecto de estas acciones, introduce el problema de los tiempos y umbrales de resistencia frente a la violencia, el momento en que estos límenes deben activarse. ¿Dónde se inician y en qué lugar concluyen las capacidades de resistencia de las colectividades? ¿Cuándo la violencia adquiere el carácter de ilegitima? Una preliminar reflexión sobre la tarea que estos umbrales cumplen frente a la violencia -habida cuenta de sus contornos, límites y extremos-, ubica sus modos de reacción en el espacio de la abolición y del rechazo. Lo anterior, bajo el supuesto de que los alcances desorganizadores de la violencia obturan el orden del progreso civilizador. Para N. Elias (1987), esta progresión en el tiempo de las comunidades humanas modifica profundamente la estructura de la personalidad de los hombres, conduciendo a la domesticación de las fuerzas naturales. Se trata de una faceta que define aspectos históricos antes que biológicos, siendo en gran parte dependiente de la revolución científica del siglo XVII. La civilización permitiría para Elias, una diferenciación de las funciones sociales, generando una marcada interdependencia entre los hombres. Esta interdependencia, consecuencia del proceso civilizador, sería engendradora del dominio de las pulsiones inmediatas. El dominio y la coerción de las tendencias destructivas no es para Elias un fenómeno desvinculado de las conquistas científicas (en particular de la física moderna). El control de la naturaleza conlleva al control social e individual, formando un encadenamiento en círculo que conforma una trilogía funcional: ninguno de estos elementos puede desarrollarse sin la presencia de los otros. Si uno de ellos se desmorona, los otros continúan en igual pendiente de destrucción (ELIAS, 1987, p. 189-190).

Si el estudio de la violencia en el ámbito político y en la conformación de las identidades ha generado el desarrollo de significativos capítulos de 
la sociología del siglo XX (ARON, 1965; WEBER, 2003; GAUCHET, 1985; BOURDIEU, 1993; WIEVIORKA, 2008), de la filosofía política (ARENDT,1972; BENJAMIN, 2010; DERRIDA, 1996), de los estudios antropológicos y culturales (LÉVI-STRAUSS, 2011; APPADURAI, 2007; MBEMBE, 2016; BHABHA, 2007; LATOUR, 1997), y de la psicología colectiva (FREUD, 1986; ENRIQUEZ, 1983; 2007), es un hecho que los problemas que ella suscita en el mundo contemporáneo se insertan en paralelismos conceptuales y éticos de difícil discriminación. Las representaciones morales y éticas que de un modo histórico han conducido a la humanidad a la suposición de la existencia del proceso civilizador, proyectan la presencia de una razón histórica asentada en un fondo de "idealidad" frente a las distintas manifestaciones de desorden que supone la violencia. Nietzsche hablaba a estos fines de la "historia monumental" del proyecto moderno, y de la omisión en este relato, de las expresiones del fanatismo, de la violencia y del asesinato. El marco de esta idealidad, de claros propósitos teleológicos y finalistas, apela sistemáticamente a la no-violencia como el modo de reacción frente a la crueldad de la violencia. Es factible observar el marco general de estas aprehensiones en el conglomerado de las medidas de prevención que se consideran para el tratamiento de la violencia. Tal es el caso de la solicitación a la que recurren distintos análisis de índole social para comprender el problema de la violencia, elaborando a estos fines, un dominio de conceptos, representaciones y valorizaciones que destacan lo que debe ser contrario a su empuje destructor y negativo. Se trata de una negatividad muchas veces convocada (en su exclusión) por la propia figura del Estado de derecho, aun si paradójicamente esa misma violencia constituye una de las piezas centrales de la prolongación de sus fundamentos.

De manera general, estas concepciones enfatizan la confrontación de la violencia frente a la preservación de los bienes culturales, desarraigándola de las fuentes mismas de la política. Lo anterior, supone comprender que, frente a la condición natural del hombre, habría que visualizar el surgimiento de una segunda condición, generadora de los contratos que llevan al desafuero de las tendencias que se dirigen en una dirección contraria a los intereses colectivos. La acuciante situación vivida en la actualidad por los problemas que la violencia genera en lo relativo a los motivos organizadores de los vínculos sociales, conduce a la crítica de estas contraposiciones. El conflicto de las identidades enfrentadas evidencia que la violencia no es el nombre exclusivo de una crueldad que opera de un modo antagónico a la institucionalidad de las 
formas políticas, ella se transforma en la violencia del poder (y en el motivo de las acciones de resistencia que pueden conformarse frente a tales operaciones).

En el plano de las elaboraciones históricas construidas a propósito de estas contraposiciones, las indagaciones de Hobbes y de Hegel organizan un cúmulo de enunciados de fuerte relevancia para comprender el espacio asignado a las relaciones de la violencia con la política. Por medio de una lectura referida a las pasiones y la violencia, estas ideas trazan ciertos aspectos a considerar para pensar la construcción imaginaria de las identidades colectivas, sus fundamentos, y su permanencia en el tiempo.

\section{Hobbes, HEgel, DE LA CRUELDAD DE LA VIOLENCIA A LA VIOLENCIA HECHA PODER}

Respecto de las grandes ideas que el Leviatán de Hobbes organiza a propósito de la violencia, distintos son los puntos de análisis que abordan las antinómicas relaciones entre guerra/paz, estado natural/estado civil, pasión/ razón. En el capítulo XIV de este texto, titulado: "De las leyes naturales primera y segunda, y de los contratos", se erige una consideración relativa a la violencia como una dimensión constituyente del estado natural del hombre, manifestación de los modos de acción del derecho natural. Para Hobbes (1983, p. 227), el jus naturale, es la libertad que cada hombre posee de utilizar su propio poder:

[...] como él quiera, para la preservación de su propia naturaleza, es decir, de su propia vida y, por consiguiente, de hacer toda cosa que en su propio juico, y razón, conciba como el medio más apto para aquello.

Vinculada la libertad al juicio y la razón que preservan la vida individual, jus et lex se oponen, como se enfrentan el derecho y la ley. El derecho consiste en la libertad de hacer o de no hacer, mientras que la ley determina y obliga. Por naturaleza, todo hombre tiene derecho a todo, y dado que la condición del hombre es la "de la guerra de todos contra todos" (HOBBES, 1983 p. 227), cada hombre responde al gobierno de su propia razón. La persistencia del derecho natural que declara la perpetuidad del dominio sobre los otros, no concede según Hobbes seguridad para hombre alguno. En el rechazo de las acciones desorganizadoras generadas por la guerra y la violencia, todo hombre tiende hacia la paz, por medio de ella es factible concebir la organización de la 
segunda ley de la naturaleza, expresión de renuncia de los derechos individuales y consentimiento de la otredad:

Que un hombre esté dispuesto, cuando otros también lo están tanto como él, a renunciar a su derecho a toda cosa en pro de la paz y la defensa propia que considere necesaria, y se contente con tanta libertad contra otros hombres como consentiría a otros hombres contra él mismo (HOBBES, 1983, p. 228).

Frente a la guerra y el derecho propio, la paz y el contrato. Relación que concretiza la renuncia a un estado natural por medio de lo que Hobbes da en llamar, "la acción voluntaria de transferencia" (HOBBES, 1983, p. 229). La justicia y la injustica son figuras mediadas de un modo posterior a la condición real del contrato. Un contrato es para Hobbes, "la transferencia mutua de un derecho" (HOBBES, 1983, p. 230).

Las acciones de rechazo frente a las tendencias expresadas por el derecho natural -condiciones propias del poder de agresión y de la guerra-, tales que la paz, la razón consensuada y la figura del contrato, equivalen a las condiciones de existencia de la esfera política. Por medio de la existencia de la república, tal esfera política no omite la utilización de violencias "legítimas" en los casos en que sea necesario sopesar la fuerza ilegitima de otro tipo de violencia. La fuerza que yace y que actúa en la ilegitimidad que constituye para el contrato la razón individual, es sinónimo de fractura, de desmoronamiento y de ruina. Por medio del contrato se reprimen las posibilidades efectivas del acontecer de tal ruptura, suponiendo igualmente la reconducción de las pasiones al ámbito de la ley y de la política (Hobbes concede un lugar destacado al temor y la muerte como vías trasformadoras de la guerra en paz). Las pasiones no mediadas suficientemente por el contrato deben por ello ser refrenadas, abolidas y reprimidas.

Debo por lo tanto enseñarse al pueblo a abstenerse de violencia para con la persona de los demás por venganzas privadas, de la violencia y hurto fraudulento de los bienes de otro, a cuyo fin es también necesario que se les enseñen las nocivas consecuencias del juicio falso por corrupción de jueces o de testigos, por el que se suprime la distinción de la propiedad y queda sin efecto la justicia, cosas éstas que están todas prescritas en los mandamientos sexto, séptimo, octavo y noveno (HOBBES, 1983, p. 413). 
El contrato no posee en exclusividad una función coercitiva, los preceptos y sus funciones represivas delimitan también las posibilidades que posee la organización social para concebir su pasado, su presente y futuro. Hobbes se refiere con ello al tránsito histórico del hombre genérico, para formular inicialmente lo que, por medio del pasado, se ha podido conceder y dar. El tiempo presente formula lo que se concede, lo que se otorga de un modo oblativo. El futuro expresa las posibilidades del porvenir por medio de lo que podrá ser concedido. No se transita colectivamente por la historia sin conceder en los derechos singulares, el proyecto de la república es para Hobbes, la materialización de dicho devenir. Aun así, el hombre es portador de una constitución oscilante, la cual se expresa por medio del conflicto entre las pasiones y la razón. Podría de este modo pensarse en una doble realidad de las producciones humanas; o bien el incremento del poder negativo e individual, violento y no consensual, o bien su contrario, es decir, la búsqueda del consentimiento. Es relevante visualizar que en estas figuras de oposición entre la negatividad de la violencia y la positividad de la política, Hobbes se convierte en el antecedente insigne de las definiciones del poder del Estado y de sus modos de hacer con el problema de las identidades. El Estado es una entidad monopolizadora de la violencia, por medio de la cual, legitima su preservación en el tiempo. Que para Hobbes (1983, p. 223-224), sin estado civil "haya siempre guerra de todos contra todos", es una aseveración que hace ingresar el registro del tiempo en la habitación política colectiva.

Pues la guerra no consiste solo en batallas, o en el acto de luchar; sino en un espacio de tiempo donde la voluntad de disputar en batalla es suficientemente conocida. Y, por tanto, la noción de tiempo debe considerarse en la naturaleza de la guerra; como está en la naturaleza del tiempo atmosférico. Pues así como la naturaleza del mal tiempo no está en un chaparrón o dos, sino en una inclinación hacia la lluvia de muchos días en conjunto, así la naturaleza de la guerra no consiste en el hecho de la lucha, sino en la disposición conocida hacia ella, durante todo el tiempo en que no hay seguridad de lo contrario. Todo otro tiempo es paz.

La represión de las tendencias desorganizadoras del hombre que ilustran la oposición entre el ámbito de las pasiones y de la razón, debe dirigirse a tal tipo de disposición, para precipitar de este modo, el abandono de estas tendencias de los tiempos de la política. Esta oposición entre guerra y paz, entre naturaleza y derecho, se desvincula en su modo de conformación de la problemática que abre el conflicto. La represión de la violencia de los 
tiempos de la política, no supone en exclusividad la sola admisión del poder de coerción de las reglas, esta invocación también argumenta el sentido "dinámico" de los motivos de tal represión. Las apreciaciones freudianas son útiles para observar el modo que la violencia posee para obrar al interior de este tipo de construcción contractual; la violencia es el elemento reprimido en el inconsciente de la política, y el contrato, la formación de compromiso que salda el antagonismo de las fuerzas implicadas.

La gran dificultad de la represión de la violencia en el dominio de la política, trae aparejado el desafuero de las fuerzas que la historizan, desestimando el nódulo dinámico que hace de la política, una expresión de la historia (esta expresa sus luchas, antagonismos y conflictos). Se adviene de este modo a la pacificación de los antagonismos y los conflictos por los medios que vuelve posible la instauración de una soberanía a-histórica, que define los móviles de cohesión del grupo, las condiciones de su existencia, los sentidos de su tránsito por la historia. La demarcación espacial es también temporal, delimitando las identificaciones grupales que brindan pregnancia a los sentimientos de carácter identitario. ¿Cómo nombrar entonces el dominio inestable que expresa la política (en sus formas de acción y de reacción) cuando uno de los elementos rectores de su historicidad permanece anulado de la lógica del proceso civilizador? El antagonismo de tendencias postulado por Hobbes, se muestra inerte frente a la situación que la violencia expresa en lo relativo a la historización de la política. Esta oposición comprende las figuras del conflicto y del antagonismo por medio de la gestión de un poder central, que desestima el dinamismo de las oposiciones y fuerzas que amenazan en todo momento con el desmoronamiento del contrato. Otra constatación referida a los sistemas políticos modernos, evidencia que estos no hacen de la violencia un elemento de último recurso para pensar la paz interna, ésta es siempre lograda por medio de la guerra externa, sostenida de un modo permanente y sistemático. En la actualidad, la violencia no es la excepción o la última vía de expresión de la exaltación de los sentimientos identitarios y nacionales, más bien los sostiene y propicia. La conformación del mundo contemporáneo antepone a la igualdad que Hobbes enunciaba para pensar la condición natural del hombre, la figura de desigualdades, constantemente reproducidas y agravadas por la violencia. Discordancia observable en los escenarios sociales y políticos en los cuales la dignidad de la vida humana es definida, así como en las mutaciones que estas definiciones figuran para nombrar formas de vida consideradas desechables y por lo tanto exterminables (OGILVIE, 2012). 
Un paso distinto es el que se define cuando los propósitos frente a la violencia no son los de la represión y el desafuero de sus tendencias, sino su conversión y superación. La violencia es aquí razonada en un plano más vasto, que implica su intrincación con el desenvolviendo del "espíritu de la historia". La historia no es considerada por Hegel como un proceso continuo, ésta debe superar-y en consecuencia convertir- en su tránsito y movimiento, la negatividad que supone la destrucción y la acumulación de la violencia. La violencia debe ser convertida y transformada por las fuerzas culturales, las cuales, en su impulso liberador, se vuelven un sinónimo de la libertad del hombre. No se trata esta vez de la exclusión que debe ser ejercida sobre la negatividad que la violencia aporta al orden civilizador (y en este sentido a su tiempo), sino de la acentuación que el poder de la razón ejerce de manera inclusiva sobre la violencia. Es en el cumplimiento del trabajo ejercido sobre la injusticia y la violencia, donde precisamente puede acontecer la efectividad de esta razón histórica.

A diferencia del tratamiento dado por Hobbes a la violencia - que la desaloja de los modos de operación de la política-, Hegel estima que su presencia es un motor central de la racionalidad política, susceptible de ser convertida por el poder transformador de la razón histórica. La acción política como práctica concreta, queda de este modo asociada a la idea de proceso que erige la historia. Para Hegel, es asunto determinar cómo la destrucción puede convertirse en construcción al interior de la historia, o cómo la construcción de un momento histórico puede ser destruido en razón de la construcción de una nueva forma de expresión del espíritu. Esta visión, es indisociable de la relación que en todo momento la política entreteje con la historia, para de este modo establecer el ámbito de las conversiones en la dirección del progreso civilizador o de la realización del espíritu absoluto. La figura del Estado asoma como la condición rectora de toda operación de conversión y transformación. Si el ejercicio transformador de la razón frente a la violencia puede ser visto en la historia, la historia es la cruda demostración de las conversiones de la violencia en tanto proceso de desnaturalización incesante. La historia es para Hegel, el terreno donde se expresa el sacrificio de los pueblos, la sabiduría de los estados, pero también las virtudes de los individuos. El gran problema para el autor de la Fenomenología del espiritu, es saber en razón de qué fines se cumplen estos sacrificios.

Sin embargo, en la medida en que la historia se nos aparece como el altar en donde ha sido sacrificada la felicidad de los pueblos, la sabiduría de los estados y la virtud de los individuos, la cuestión que se presenta necesariamente es la de saber para quien, a qué fines estos inmensos sacrificios han sido realizados (HEGEL, 1996, p. 103). 
En cada uno de estos sacrificios, Hegel observa el cumplimiento de un destino substancial, el verdadero resultado de la historia universal; sacrificar la naturaleza al orden de la cultura y de la ley. Al trabar un comercio indisociable con la historia, la política como concepto se convierte en una expresión de la historia universal. La filosofía de la historia transita de este modo en la dirección de los elementos que forjan la filosofía del derecho. En síntesis, los argumentos de Hegel referidos a la violencia, concentran distancias significativas respecto de las construcciones represivas con las que Hobbes ordena un pensar relativo a la violencia al interior del orden político. Por medio de la violencia, Hegel piensa en la dificultad que existe para asociar la política (en tanto práctica) con la historia (en tanto proceso). Es por medio de una concepción relativa al progreso del orden civilizador que esta dificultad podrá ser superada, volviendo posible la trasformación de los impulsos desorganizadores de la violencia. Sinónimo de este progreso es la educación, que cumple con actuar sobre los hábitos, los sentimientos y los "instintos". El Estado se convierte en el agente superior en el cual Hegel piensa al momento de considerar la acción liberadora que la razón cumple sobre las pasiones.

\begin{abstract}
El estado de naturaleza es antes bien, el estado de la injusticia, de la violencia, del instinto natural desencadenado, de las acciones y de los sentimientos inhumanos. La sociedad y el Estado imponen aseguradamente límites, lo que ellos limitan son estos sentimientos amorfos, estos instintos brutos y -más tarde- las opiniones y las necesidades, los caprichos y las pasiones que han sido creadas por la civilización. Esta limitación es debida a la mediación por la cual se produce la voluntad consciente de la libertad tal que ella es en verdad según la Razón y según el concepto. (HEGEL, 1996, p. 142)
\end{abstract}

En su abordaje, Hegel comprende desde diversos ángulos el rol historizante y subjetivante de la violencia. Esta no se encuentra ausente ni en la recurrencia de solicitación de los derechos del proletariado, ni en los modos de fundación del derecho. La violencia estaría igualmente concernida en los medios que ese derecho emplea para realizar la práctica de su propia conservación. Es importante notar que la lectura de Hegel no se realiza considerando la represión de la negatividad que esta dimensión aporta para la constitución de lo político, aun si ella permanece adosada a la admisión de su conversión en figuras ideales fundadas en el poder de la razón. No podría por ello enunciarse que donde termina la violencia, se inicia el reinado de la razón y el derecho.

Tanto Hobbes como Hegel, ofrecen un relato para comprender las difíciles articulaciones entre violencia y política. Ambas concepciones ilustran 
el complejo devenir de la institucionalidad política cuando ella es pensaba por los medios que ofrece la violencia. Ya sea por medio de su abolición o superación, la violencia nombra el devenir de las colectividades humanas, los elementos a considerar a los fines de su preservación, la forma de capturar el sentido de su existencia. Sin embargo, y a pesar de las distancias de estas concepciones, sus elaboraciones refieren un punto en común, como es el sentido trágico de la relación que une a la política con la violencia. Este aspecto trágico de la política, también indica las formas de poder que supone el derecho en su fundación y conservación, y como ese poder puede ser útil a los fines de las políticas de la violencia que instauran las derivas identitarias.

El psicoanálisis introduce un acento trágico para la comprensión de la violencia. Si la deriva de sus enunciados va en la dirección de mostrar que fundar derecho es fundar poder, y que, en ese sentido, la fundación del derecho es un acto de la manifestación inmediata de la violencia, las condiciones de esta violencia rechazan la asunción de prácticas inamovibles, pues estas prácticas suponen evidentemente un condicionamiento de tipo histórico. Definir la presencia de la violencia de un modo trágico, lleva a establecer la inscripción de una tesis negativa, por cuanto la violencia no puede distanciarse de los modos en que la historia es producida y escrita. Es en esta historia que podemos observar la inscripción de sus alcances y efectos, a quienes la utilizan, y sobre quienes recae. Esta vertiente negativa de la violencia, aparece detenidamente abordada en los textos de "vocación cultural" que Freud redacta durante los años de 1920-1930.

\section{El PSiCOANÁlisis FRENTE A LA ViOlenCia, LA POlíticA Y los RELATOS IDENTITARIOS}

Orientando una reflexión relativa al impacto de las tendencias pulsionales en la vida social, los postulados freudianos explicitan la relevancia que el odio y el amor cumplen en la organización de la vida colectiva. La presencia de la alteridad dada por el semejante, conforma la realidad de un objeto que puede ser amado, pero también odiado o aniquilado. El narcisismo de las "pequeńas diferencias" es para Freud (1986, p. 111), el material de base que distribuye la serie de estos opuestos, conduciendo a que una sociedad instaure su sentimiento de comunidad en el establecimiento de su "pequeño círculo cultural." Esta vía ofrece un punto de fuga para los sentimientos de agresión y de hostilidad a los extraños. Las satisfacciones brindadas por 
las narraciones de los pequeños círculos culturales, facilitan para Freud, la cohesión de los miembros de la comunidad. Los relatos que organizan los sentimientos de pertenencia a un todo, son la traducción de las dificultades inherentes a la esencia de la idea de cultura, y que ningún ensayo de reforma podría superar. En el relato identitario acecha la "miseria psicológica de la masa" (FREUD, 1986, p. 112), su incertidumbre, establecida principalmente por la identificación recíproca entre los participantes.

Puede observarse que los postulados psicoanalíticos referidos al poder de la agresión y de la violencia, destacan la función de cohesión que cumplen estas tendencias, sin ser abolidas, ellas producen el sentimiento de comunidad anhelado. Las máximas de Freud no explicitan la simple contraposición entre las tendencias individuales y la renuncia a estas inclinaciones por medio de la creación de una voluntad colectiva. Es indudable que sus enunciados las suponen, pero mediadas por una relación que resalta su carácter inconciliable. Sus tesis tampoco suponen la conversión devastadora de la violencia por intermedio de una razón dialéctica, que Hegel ubica como un elemento central del curso civilizador. Para el psicoanálisis, la violencia que se inscribe en la historia llama al diferimiento de su aspecto devastador, tarea supuesta para las formaciones culturales en el horizonte de un desmoronamiento político-colectivo nunca del todo desestimado (FREUD, 1986, p. 140). Admitir la violencia en el curso de la historicidad del hombre, será siempre incluirla en el dominio de una fuerza $\sin$ fin. Devastación sin fin, desolación sin freno, violencia interminable. Pero concebir la presencia de una violencia sin fin, es también incluir la negación de sus alcances teleológicos (no solamente no cesa, sino que no posee fin alguno). La negatividad de las tesis freudianas recae de un modo directo sobre las estratagemas considerados para pensar su cesar, y su contextualización en la historia por medio de criterios no finalistas. Si la violencia nominativa que opera en los "pequeños círculos culturales" no puede ser abolida y/o convertida, las acciones de rechazo y resistencia a este tipo de acciones deben en consecuencia proceder por medio del diferimiento. Son estas acciones de diferimiento de la violencia las que deben cumplirse al interior de "estrategias concretas", pensadas en un tiempo real por parte de las colectividades políticas (BALIBAR, 2004, p.122). La dimensión trágica y negativa que se formula en las tesis freudianas relativas a la violencia, conduce a la crítica de los sentidos culturales que brindan sostén a la permanencia de lo político, sin omitir el problema de su preservación en el tiempo. La violencia interroga estos sentidos, indica sus fragilidades, estos no son nunca inmutables, obedecen al esfuerzo de las colectividades, y no poseen 
en consecuencia correspondencia con sentidos extraídos del espíritu inmemorial de los pueblos.

La rúbrica trágica que afecta a la política en las relaciones que ella mantiene con la violencia, suscita para el psicoanálisis apreciaciones de un carácter indudablemente ético. Por cuanto profundiza en la situación trágica que toda elaboración sobre la violencia enfrenta cuando esta última es vista como una disposición fundamental de la vida humana. Disposición que se encuentra en la historia, en el desarrollo de los imaginarios del hombre, siempre reactiva a que su entendimiento sea llevado a la simple gestión y administración de los problemas humanos (BERGERET, 1994). Emanada del liberalismo económico, dicha gestión de los conflictos prescinde de la dimensión del apremio, de la tensión, de la dislocación de tendencias, de los síntomas que se anudan en toda formación social. La violencia hace suyos estos fenómenos para explicitar la serie de los daños, de los sufrimientos o de las opresiones que pueden ser la consecuencia de poderes inveterados.

En lo relativo a los vínculos que pueden ser observados entre la dimensión ética y política, se trata entonces para Freud, de dos tipos de violencia. En primer lugar, aquella que puede ser definida de material "fundante" para los fines de las creaciones culturales, veta sobre la cual se concentra el trabajo de incorporación de las tendencias destructivas por intermedio de la inscripción de la culpabilidad súper-yoica, al hacer recaer este tipo de violencia en la interioridad del sujeto (FREUD, 1986, p. 128). Comprendida como adquisición cultural, esta introyección marca los gradientes de superposición y diferenciación entre un súper-yo anímico y otro de naturaleza cultural. No se trata empero de la simple asimilación de formaciones inhibitorias que encaminan la adaptación requerida por la cultura, puesto que estas formaciones no pueden ser desvinculadas de la presencia de la agresión, ellas son la forma degradada de un cometido agresivo dirigido al exterior. Las formaciones psíquicas que articulan la conformación de los ideales y de la conciencia moral, son para Freud, herederas de los vínculos precoces mantenidos por el niño con sus progenitores, su relevo en el plano psíquico, siendo por ello una expresión de la degradación de estos vínculos.

Sin desligarse del primer tipo de violencia, una segunda manifestación puede ser ordenada como consecuencia de las inconsistencias que la civilización evidencia para refrenar la totalidad de las exigencias pulsionales. Las tesis de Freud avanzan en la dirección de evidenciar que las operaciones de incorporación de los baluartes culturales por parte de los individuos, no son 
nunca totales (Freud se refiere al sentimiento de culpa y la formación de los ideales propiciada por una faceta del súper-yo). Esta operación de insuficiencia e inconsistencia de las coerciones culturales, precisa el carácter refractario que la violencia guarda frente a los fines de las construcciones políticas.

Esta violencia refractaria, torna legítima la imposibilidad una abdicación total de la violencia, de la mutación razonada de sus exigencias. La violencia refractaria como vertiente impolítica de la política, puede en todo momento conducir a la agitación de los motivos que son propios a la política, a su zozobra y desmoronamiento. El problema es entonces la delimitación de los umbrales de tolerancia frente a esta faz refractaria, el punto donde estos límenes definen lo extremo e intolerable. Esta dimensión trágica de la política, devela su condición inconsistente, pero también sus potencialidades de creación y re-invención. Por medio de estas denominaciones, la violencia deviene hecho histórico, incertidumbre del acontecer social. Son estas angustias del "desmoronamiento" y del ser social "incompleto", las que son utilizadas por las políticas identitarias en sus afanes por colmar las incertidumbres que operan al interior de las comunidades.

La política se asienta sobre este fondo informulable, introduciendo el obrar de la ficción (fictio) en los ideales socio-simbólicos, como la vía que difiere y simboliza el escozor de los derrumbamientos eventuales. La desdicha de este duelo de la política, es la reacción contraria, aquella que se dirige al establecimiento de fundamentos para colmar sus acciones inconsistentes por medio de la creación de sentidos absolutos. Las derivas identitarias traban un comercio con este tipo de sentidos, convirtiendo a la violencia en una formación de lo extremo.

Que los sentidos políticos obren por medio de la lógica de lo negativo, es volver plausible la existencia de sus fragilidades, mostrando el fin de la labor cultural de la política; re-inventar permanentemente el sentido de sus fundamentos en el diferimiento que establece para incidir sobre la dimensión inconvertible de la violencia. De este modo, la insistencia freudiana no es la de considerar la presencia de la violencia como un agente disruptor de lo social, su propósito no es tampoco el de dirigir una reflexión desde la cultura para pensar en las condiciones internas y destructivas del individuo. Freud piensa desde las condiciones que son propias a la vida del hombre, desde la dinámica pulsional, para de ese modo y en un segundo momento, concebir la cultura como un andamiaje que se moviliza por medio de la intrincación de estas dinámicas, donde el odio, el amor, la agresión y la violencia, ocupan un lugar determinante. Desde la hiperpotencia de la vida pulsional es que Freud concibe la fragilidad del 
hombre, pero también las continuidades que esa vida pulsional permite para las representaciones relativas a la ciudad, a la sexualidad, al conflicto y la muerte. $\mathrm{Si}$ para Hegel la lectura de la violencia se desarrolla en el ámbito de las relaciones que esta guarda con la historia, para Freud, esta negatividad no es convertible, ella se erige al modo de una negatividad radical. La lectura del Malestar en la Cultura nos transmite que esta tensión debe volver transparente el conflicto de las resistencias o suponerlo al menos, admitiendo que, en su constitución, es toda la sociedad la que descansa en estas respuestas de resistencia frente a la negatividad radical de la violencia. Es esta misma visión la que brinda el derecho a lo sujetos de emanciparse de las leyes y reglamentaciones cuando ellas tienden a eclipsar el sentido de las resistencias. La dimensión anímica y colectiva que el psicoanálisis esboza para considerar el problema de la violencia, y la relación que ella guarda con la creación de los sentimientos identitarios, es útil a los efectos de mostrar que la extremidad de la violencia, posee una estructura propia, constituida por la unidad de contrarios, por la fusión de valores y de categorías adversas.

Estos ángulos de análisis, vuelven transparente que la "institución" de la ficción humana contiene en germen la posibilidad de su destrucción, debiendo apelar por ello a acciones de resistencia permanentes. Esta destrucción eventual encuentra las resistencias posibles en lo que E. Balibar (2010, p. 143-191) denomina "estrategias de civilidad", para acorde a este concepto, entender las posibilidades de su perduración. Para Balibar, esta expresión no es el contrario de incivilidad, sino la política de las condiciones mismas de lo político. Pensando en el sentido de la institución de lo político, para Balibar, la política no puede situarse por fuera del campo de la violencia. Razón por la cual, el problema de la civilidad y sus estrategias, no podría reducirse frente a la violencia a una elección abstracta entre violencia y no violencia, o entre violencia y derecho. La civilidad debe mantenerse en la red de los sentidos que unen de manera permanente la violencia y la política. De ese modo se pueden discriminar ciertos umbrales, ciertas variaciones asociadas a la representación de lo insoportable y a la posibilidad de una inversión de tendencias. Estos umbrales actúan como los límites de la institución, puntos de la presencia de lo inhumano en el seno de lo humano, o el punto de encuentro de lo político y su Otro, lo impolítico. Estos límites y umbrales no pueden jamás ser el objeto de una decisión definitiva, sino una tentativa reiterada de la inteligencia y de la confrontación. Como se señalara, en el ámbito colectivo, la figura de la extrema violencia es la abolición de toda resistencia a la violencia, obturando toda posibilidad de dialéctica y de creación. La sedimentación de los sentidos de la política es uno de los alcances de esta obturación, modo de acción y representación del tiempo social que es concebido por las derivas identitarias. De 
allí su peligro, la negación del tiempo, la creación de sentidos no sancionados por lo que la política denomina: la institucionalidad democrática.

\section{Conclusión}

Establecidas las coordenadas para pensar los sentidos políticos que se desenvuelven al interior de las lógicas identitarias, la postura freudiana surge desde su antítesis. Esto es, concebir que las condiciones de lo político se formulan en las mismas coordenadas de su imposibilidad, su vecindad es absoluta. Para Freud, pensar la política junto a la violencia, es rechazar el sentido mismo de lo político, denunciarlo como la ilusión de la unificación de lo Uno. Su cometido es abigarrar esta ilusión por medios diversos, ya sea por medio del análisis de las representaciones religiosas, en las inquietudes referidas a la guerra, en la relación de las masas con sus líderes, o en las inconsistencias que la política expresa cuando ella es considerada en su raigambre cultural. Todos estos aspectos encaminan el mismo tipo de reflexión; mostrar el sentido imaginario de las identificaciones producidas. "La política existe cuando - y solamente si- dejamos que la realidad proponga un punto de real" (BADIOU, 1985, p. 20).

La formulación de lo político sufre de este modo el riesgo de su eventual informulación. Si el hombre político freudiano no se asienta en la incivilidad, esto le permite la posibilidad de la revuelta, de la desobediencia civil cuando se trata del sometimiento a un sistema civil inveterado. La civilidad queda vinculada de este modo a movimientos de identificación como de (des) identificación que pueden en todo momento, cuestionar el orden de las sujetaciones. Esto es lo que Lefort llamó la "invención democrática" (1981). Las acciones de insurrección no pueden tener sentido más que en el contexto de una ley o en referencia a un orden comunitario que ella reconoce de manera fictiva, tendiendo de ese modo a reconstruirlo. En este punto se encuentra el enigma de lo político y en todo caso su aporía, ya que es preciso para fundar la comunidad, el acontecimiento constante de someterla permanentemente a cuestionamiento.

Finalmente, todas estas ideas podrían resumirse en una formulación especulativa: la única manera de evitar que el fundamento democrático de la política sea inmediatamente contradicho y negado en su institución por las políticas de lo extremo, es indudablemente la acción de abolir su fundamento mismo. Es decir, concebir la política como una ficción absoluta, como una institución sin fundamentos e irremediablemente contingente. Pensar un fundamento para las lógicas de habitación colectiva, es lo que realmente 
podría constituir el punto extremo. Es en esa certitud donde pueden reposar los motivos del terror y de lo extremo. Es entonces la posibilidad aleatoria exclusivamente práctica de distanciar el terror, de diferirlo relativamente al menos por un largo tiempo, lo que sienta las bases de lo dado en llamar trágico, pero también democrático, al momento de considerar el rol de la violencia en la política.

BILBAO, A.; JOFRÉ, D. Identitary narrations, violence, politics and civility: psychoanalysis against collective dreams. Trans/form/ação, Marília, v. 43, n. 4, p. 17-42, Out./Dez., 2020.

\begin{abstract}
This article establishes an analysis related to the senses that organize the narratives of identity policies, considering their historical and social links with the dimension of extreme violence. To achieve this, certain historical scopes of political philosophy are taken into account, analyzing the relationships they show with Freudian proposals specific to the cultural dimension of politics. An equally important number of statements are elaborated on the political actions that can be established against the devastating course of identity violence. devastador de la violencia identitaria.
\end{abstract}

Keywords: Violence. Politics. Identity. Civilization. Psychoanalysis.

\title{
REFERENCIAS
}

ARENDT, Hannah. Les origines du totalitarisme, le système totalitaire. Paris: Seuil, 1972.

APPADURAI, Arjun. El rechazo de las minorías. Barcelona: Tusquets, 2007

ARON, Raymond. Démocratie et totalitarisme. Paris: Gallimard, 1965.

BADIOU, Alain. Peut-on penser la politique? Paris: Seuil, 1985.

BALIBAR, Étienne. Derecho de ciudad. Cultura y política en democracia. Buenos Aires: Nueva Visión, 2004.

BALIBAR, Étienne. Violence et civilité. Wellek library lectures et autres essais de philosophie politique. Paris: Galilée, 2010.

BENJAMIN, Walter. Critique de la violence. Paris: Payot, 2010

BERGERET, Jean. La violence et la vie: la face cachée de l'oedipe. Paris: Payot, 1994.

BHABHA, Homi K. El lugar de la cultura. Buenos Aires: Manantial, 2007.

BOURDIEU, Pierre. La misère du monde. Paris: Seuil, 1993. 
CRÉPON, Marc. La Guerre des civilisations. La culture de la peur, II. Paris: Galilée, 2010. DERRIDA, Jacques. Le monolinguisme de l'autre. Paris: Galilée, 1996.

ENRIQUEZ, Eugène. De la horde à l'état. Essaie de psychanalyse du lien social. Paris: Gallimard, 1983.

ENRIQUEZ, Eugène. Clinique du pouvoir; les figures du maître. Paris: Érès, 2007. ELIAS, Norbert. La société des individus. Paris: Fayard, 1987.

FREUD, Sigmund. El malestar en la cultura. In: FREUD, Sigmund. Tomo. XXI. El porvenir de una ilusión. El malestar en la cultura y otras obras (1927-1931). Buenos Aires: Amorrortu, 1986.

GAUCHET, Marcel. Le désenchantement du monde. Paris: Gallimard, 1985.

GOUREVITCH, Philip. Queremos informarle de que mañana seremos asesinados junto con nuestras familias: historias de Ruanda. Barcelona: Destino, 1998.

HEGEL, Georg Wilhelm Friedrich. La raison dans la histoire. Paris: Plon, 1996.

HOBBES, Thomas. Leviatán. Madrid: Editorial Nacional, 1983.

HUNTINGTON, Samuel P. Le choc des civilisations. Paris: Odile Jacob, 1997.

LATOUR, Bruno. Nous n’avons jamais été modernes. Essai d'anthropologie symétrique. Paris: la Découverte, 1997.

LEFORT, Claude. L'invention démocratique: les limites de la domination totalitaire. Paris: Fayard, 1981.

LÉVI-STRAUSS, Claude. L'anthropologie face aux problèmes du monde moderne. Paris: Seuil, 2011.

MBEMBE, Achille. Politiques de l'inimitié. Paris: la Découverte, 2016.

NIETZSCHE, Fiedrich. Considerations inactuelles. Paris: Aubier montaigne, 1964

OGILVIE, Bertrand. L'homme jetable. Essai sur l'exterminisme et la violence extrême. Paris: Amsterdam, 2012

RANCIÈRE, Jacques. La haine de la démocratie. Paris: la Fabrique, 2005.

ROUSSEAU, Jean-Jacques. Discours sur l'origine et les fondements de l'inégalité parmi les hommes. Paris: Librairie générale francaise, 1996

WEBER, Max. L'éthique protestante et l'esprit du capitalisme. Paris: Gallimard, 2003.

WIEVIORKA, Michel. El racismo: una introducción. Barcelona: Gedisa, 2009.

WIEVIORKA, Michel. Neuf leçons de sociologie. Paris: Robert Laffont, 2008.

Recebido: 10/9/2018

Aceito: 23/02/2020 